\title{
Synergistic antifungal effect of fluconazole unesp combined with quorum sensing molecules of Candida parapsilosis stricto sensu against Trichophyton rubrum
}

T. H. Lemes, ${ }^{1}$ G. S. Torrezan, ${ }^{1}$ L. O. Regasini, ${ }^{1}$ B. G. Almeida, ${ }^{1}$ M. H. Caetano, ${ }^{1}$ N. S. Brizzotti, ${ }^{2}$ M. D. Ribeiro, ${ }^{2}$ J. P. Z. Siqueira, ${ }^{2}$ E. M. Castilho ${ }^{2}$ and M. T. G. Almeida ${ }^{2}$

\begin{abstract}
'São Paulo State University (Unesp), Institute of Biosciences, Humanities and Exact Sciences (Ibilce), Campus São José do Rio Preto Brazil; ${ }^{2}$ Medicine School of São José do Rio Preto - Brazil

Contacts: margarete@famerp.br, lemes_th@outlook.com
\end{abstract}

\section{INTRODUCTION}

The physical chemical interactions present in mixed microbiota niches induce changes in the physiology of microorganisms, thereby affecting cellular viability;

$>$ The mechanism of these interactions should be explored, and the in vitro screening of new antifungal molecules is essential for the success of new therapeutic approaches.

\section{OBJECTIVES}

The present study evaluated the synergistic interaction between a pure culture extract of Candida parapsilosis and fluconazole against Trichophyton rubrum.

\section{MATERIAL AND METHOD}

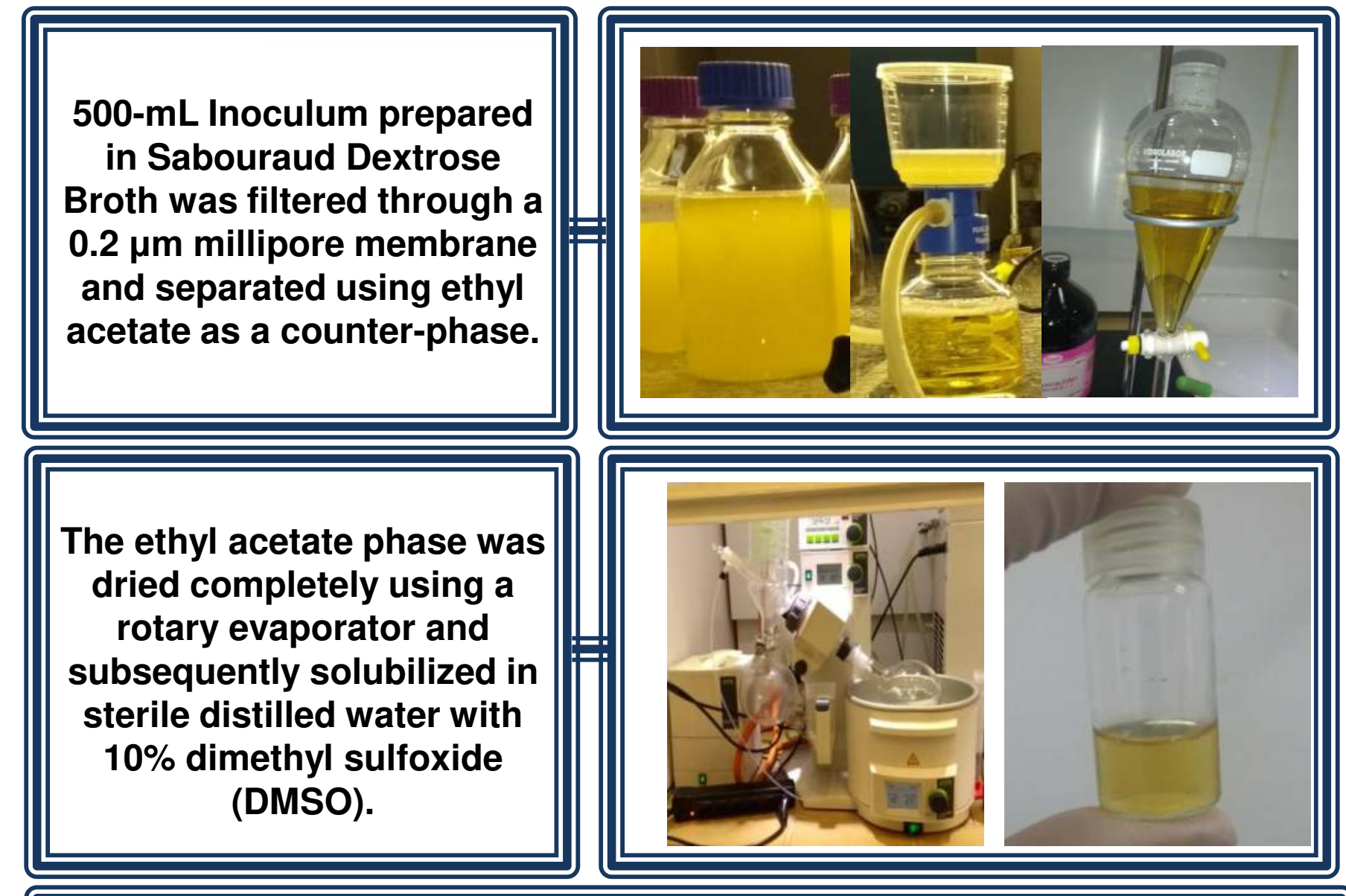

Minimal Inhibitory Concentration (MIC) and a checkerboard microdilution assay with fluconazole was performed to evaluate the synergistic interaction with the extract based on the calculation of the fractional inhibitory concentration index (ICIF);

ICIF = (MIC fluconazole in the mix / MIC fluconazole alone $)+($ MIC extract in the mix / MIC extract isolated)

Values $\geq 0,5$ indicate significant interactions.

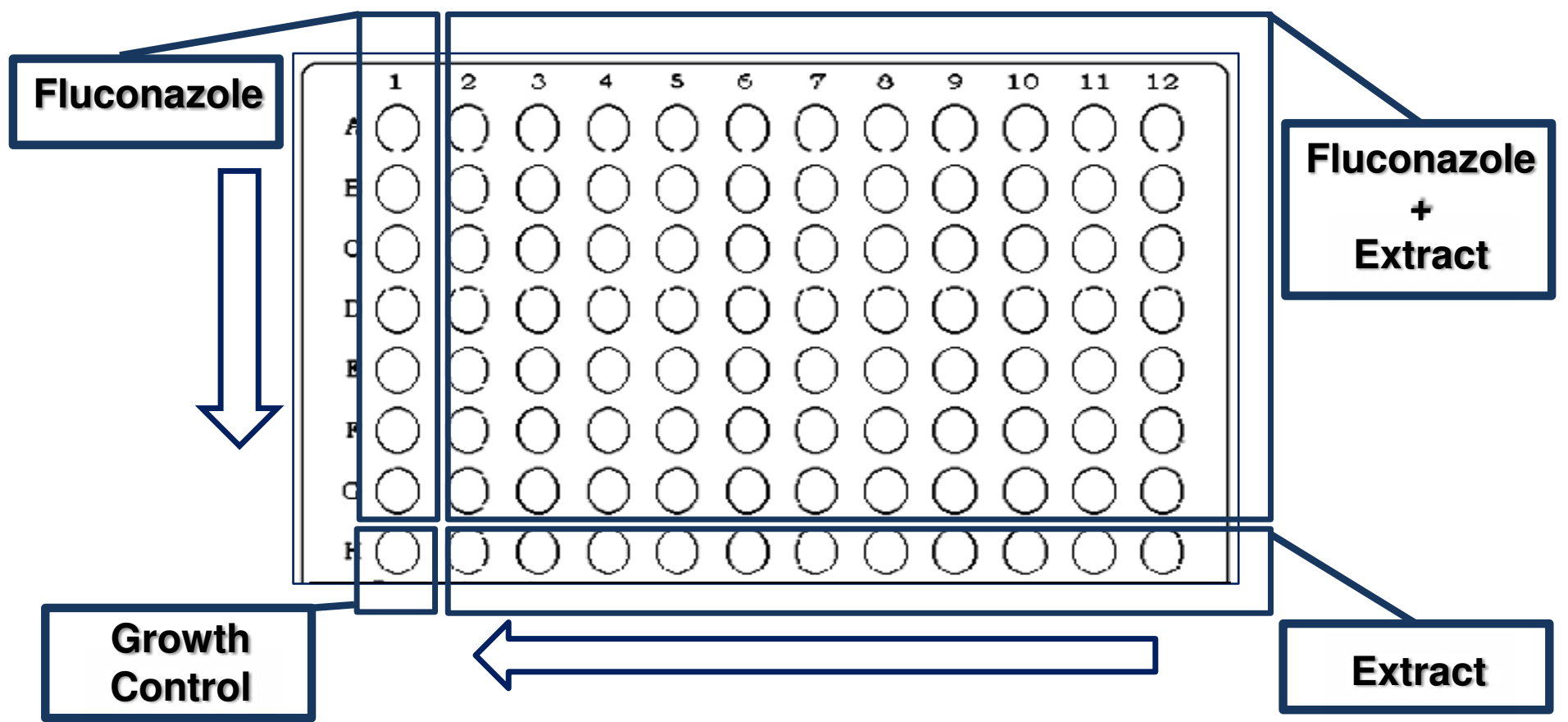

\section{RESULTS}

D The combination of culture extract of $C$. parapsilosis and fluconazole showed a synergistic interaction against $T$. rubrum (ICIF value of 0.03 ) . MIC for fluconazole decreased from 8 to 0,25 $\mu \mathrm{g} / \mathrm{mL}$ when combined with the extract (Figure 1).

Figure 1: Checkerboard microdilution assay
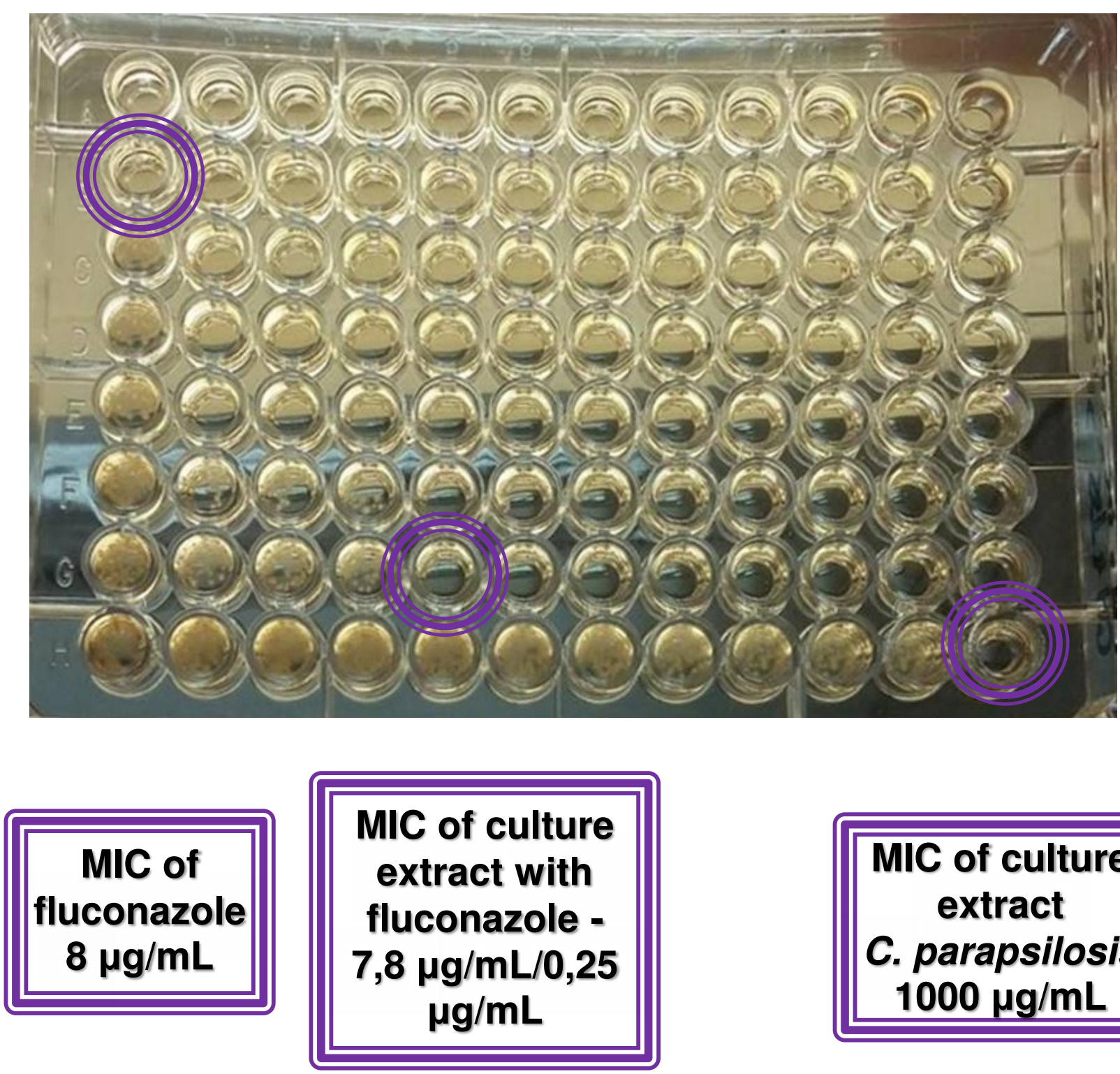

\begin{tabular}{|c||}
\hline MIC of culture \\
extract \\
C. parapsilosis \\
$1000 \mu \mathrm{g} / \mathrm{mL}$ \\
\hline
\end{tabular}

\section{DISCUSSION AND CONCLUSION}

$>$ The extract of C. parapsilosis shows antifungal activity against $T$. rubrum;

$>$ The action of the extract is greater in association with an azole derivative, thus proving synergy;

$>$ In the future, the isolation and identification of extract compounds may allow new therapeutic approaches in the control of fungal infections.

\section{REFERENCES}

> Dixon EF, Hall RA. Noisy neighbourhoods: Quorum sensing in fungalpolymicrobial infections. Cell Microbiol. 2015;17(10):1431-41

> Kumar SN, Siji J V., Nambisan B, Mohandas C. Activity and synergistic interactions of stilbenes and antibiotic combinations against bacteria in vitro. World J Microbiol Biotechnol. 2012;28(11):3143-50.

\section{FINANCIAL SUPPORT}

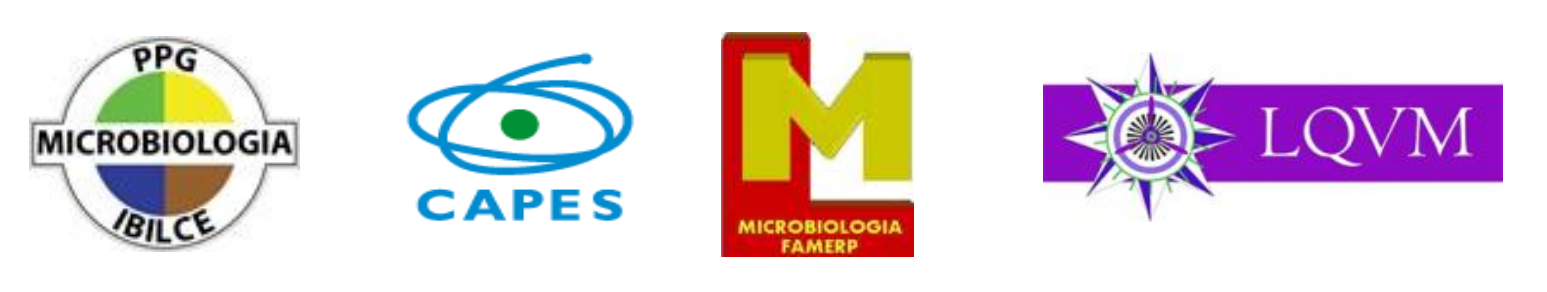

